Article

\title{
Attenuation of UVB-Induced Photo-Aging by Polyphenolic-Rich Spatholobus Suberectus Stem Extract Via Modulation of MAPK/AP-1/MMPs Signaling in Human Keratinocytes
}

\author{
Kyoo-Ri Kwon ${ }^{1,+}{ }^{\text {, Md Badrul Alam }}{ }^{1,2,+} \mathbb{0}$, Ji-Hyun Park ${ }^{1}$, Tae-Ho Kim ${ }^{3}$ and Sang-Han Lee ${ }^{1,2, *(1)}$ \\ 1 Department of Food Science \& Biotechnology, Kyungpook National University, Daegu 41566, Korea; \\ rbfl0116@knu.ac.kr (K.-R.K.); mbalam@knu.ac.kr (M.B.A.); wlgus6744@knu.ac.kr (J.-H.P.) \\ 2 Food and Bio-Industry Research Institute, Inner Beauty/Anti-ageing Center, Kyungpook National University, \\ Daegu 41566, Korea \\ 3 Biomedical Research Institute, Kyungpook National University Hospital, Daegu 41944, Korea; \\ kimth0929@ynu.ac.kr \\ * Correspondence: sang@knu.ac.kr; Tel.: +82-53-950-7754 \\ + These authors contributed equally to this work.
}

Received: 25 April 2019; Accepted: 7 June 2019; Published: 14 June 2019

check for updates

\begin{abstract}
It is well known that ultraviolet light activates mitogen-activated protein (MAP) kinase by increasing the reactive oxygen species (ROS) in the body, enhancing activating protein 1(AP-1) complexes (c-Jun and c-Fos), increasing matrix metalloproteinases (MMPs) and degrading collagen and elastin. In this study, we confirmed that polyphenolic rich Spatholobus suberectus (SS) stem extracts suppressed ultraviolet (UV)-induced photo-aging. The major active components of SS stem extracts were identified as gallic acid, catechin, vanillic acid, syringic acid and epicatechin. The aqueous and ethanolic extracts of the stem of SS (SSW and SSE, respectively) significantly reduced the elastase enzyme activity. Moreover, both extracts were suppressed the ROS generation and cellular damage induced by UVB in HaCaT cells. Our results also revealed that SSE could regulate the expression of MMPs, tissue inhibitor of matrix metalloproteinase (TIMP)-1, collagen type I alpha 1 (COL1A1), elastin (ELN) and hyaluronan synthase 2 (HAS2) at their transcriptional and translational level. Furthermore, SSE was blocked the UVB-induced phosphorylation of mitogen-activated protein kinases (MAPKs), nuclear factor-kappa B (NF-kB) and c-Jun. Moreover, combination of syringic acid, epicatechin and vanillic acid showed strong synergistic effects on elastase inhibition activity, in which the combination index $(\mathrm{CI})$ was 0.28 . Overall, these results strongly suggest that the polyphenolics of SSE exert anti-ageing potential as a natural biomaterial to inhibit UVB-induced photo-aging.
\end{abstract}

Keywords: anti-aging; Spatholobus suberectus; matrix metalloproteinases (MMPs); collagen type I alpha 1 (COL1A1); elastin (ELN); mitogen-activated protein kinase (MAPK)

\section{Introduction}

Skin aging is affected by many factors, such as ultraviolet radiation (UVR), oxidative stress, and inheritance. Among them, photoaging accounts for about $80 \%$ of skin aging [1]. UVR is divided into three wavelengths, including UVA (320-400 nm), UVB (290-320 nm), and UVC (200-290 nm). While UVC is absorbed by the ozone layer, UVA and UVB can reach the surface of the earth [2]. While most biomolecules cannot absorb UVA, UVB is predominantly injurious to living organisms. UVB contributes to detrimental effects directly through the production of reactive oxygen species (ROS) which is associated with DNA damage and inflection of gene expression. UVB initiates a 
photo-oxidation reaction primarily on the epidermis of the skin via augmentation of the cellular ROS level that causes imbalance of the skin antioxidant, sequentially accelerating photoaging [3,4]. UVB not only hinders collagen synthesis and promotes its breakdown, but also boosts the degradation of elastin in fibroblasts, resulting in the loss of skin elasticity which make deep wrinkle formation [5].

Collagen constitutes about $70 \%$ of the dermal layer and both matrix metalloproteinases (MMPs), and tissue inhibitors of matrix metalloproteinases (TIMPs) play a pivotal role in collagen degradation in epidermal keratinocytes and dermal fibroblasts. Up to now, 28 MMPs and 4 TIMPs have been identified [6]. MMPs are a family of zinc-dependent enzymes which are responsible for the degradation of collagen and extracellular matrix (ECM) components [7]. Type I collagen, which constitutes about 80 to $90 \%$ of the skin, is mainly controlled by MMP-1 (type I collagenase) and MMP-3 (stromelysin-1), whereas MMP-2 (gelatinase-A) and MMP-9 (gelatinase-B) degrade gelatin; moreover MMP-2, MMP-7 (matrilysin-1), and MMP-12 (metalloelastase) degrade elastin [8]. Not only in response to UVB, UVA and blue light, the level of MMPs in the skin is highly up-regulated $[3,4,9,10]$, therefore, the prevention of UVB-induced up-regulation of MMPs is one of the target pathways to inhibit wrinkle formation and prevent skin aging.

In living cells, ultraviolet (UV)-irradiation activates mitogen-activated protein kinase (MAPK) and regulates nuclear factor-kappa $B(N F-k B)$ expression by generating reactive oxygen species (ROS) $[3,4]$. MAPK, is an enzyme family, consisting of three types: extracellular signal-regulated kinase (ERK), c-Jun N-terminal kinase (JNK), and p38 kinase, which are involved in cell proliferation, differentiation, apoptosis, and inflammation. The MAPK pathways also regulate the transcription factor activating protein 1 (AP-1), a heterodimer comprised of c-Fos and c-Jun, which, in turn, up-regulates MMPs in the skin $[11,12]$.

Various synthetic materials have been developed as skin anti-aging agents and retinoid is the most popular among them. Retinoid is a synthetic analog of vitamin A consisting of retinoic acid and retinol (vitamin A) which promotes collagen synthesis in photoaged skin and inhibits the expression of MMPs [13]. Retinoic acid also promotes elastin and collagen synthesis [14]. However, retinoid is also reported to cause skin and liver toxicity and diseases, such as paronychia [14]. Owing to safety and lack of side effects, natural materials are being considered for the development of effective and safe anti-photoaging agents in the field of cosmetic research and development.

Spatholobus suberectus (SS) is a climbing shrub plant containing a red resin, belonging to the Leguminosae family, and mainly grows in China (Figure 1A). The stem of SS is known as "Gye-Hyeol-Deung" in Korea and "Ji Xue Teng" in China because it produces a red juice like chicken's blood [15]. Traditionally, the stem of SS has been applied to treat inflammation-induced thrombosis and peripheral blood vessels [16]. Numerous scientific reports have revealed that SS has anti-hepatitis C virus activity [17], antiplatelet [18], anti-breast cancer [19], antioxidant [20], chondrogenesis stimulating [21], antiviral [22], and protective effects against cerebral ischemia [23]. It has also been reported that SS has the potential to regulate cartilage-related MMPs and TIMPs [21] and anti-inflammatory activity [23].

Based on previous reports, it was hypothesized that the aqueous and ethanolic extracts of Spatholobus suberectus stem (SSW and SSE, respectively) would play a pivotal role in human healthy skin homeostasis by mediating functionality and nutritional balance in body. However, there have been no reports regarding the potential dermatological application of the SS stem. SS extracts were considered in this study to evaluate its effects against photo-aging in human keratinocyte cultures and the underlying mechanism by which SS extract mitigates the appearance of wrinkles. Therefore, in this study, in order to assess what kinds of nutritional food ingredients are involved in the plant and how the nutrients can be applied for skin care for the better healthy life, we determined its effect on skin wrinkles and elasticity, as well as the mechanism to assess whether it has sufficient value as a natural material to suppress aging. This can contribute to the development of novel and useful cosmetic agents, supplements, and functional foods. 
(A)
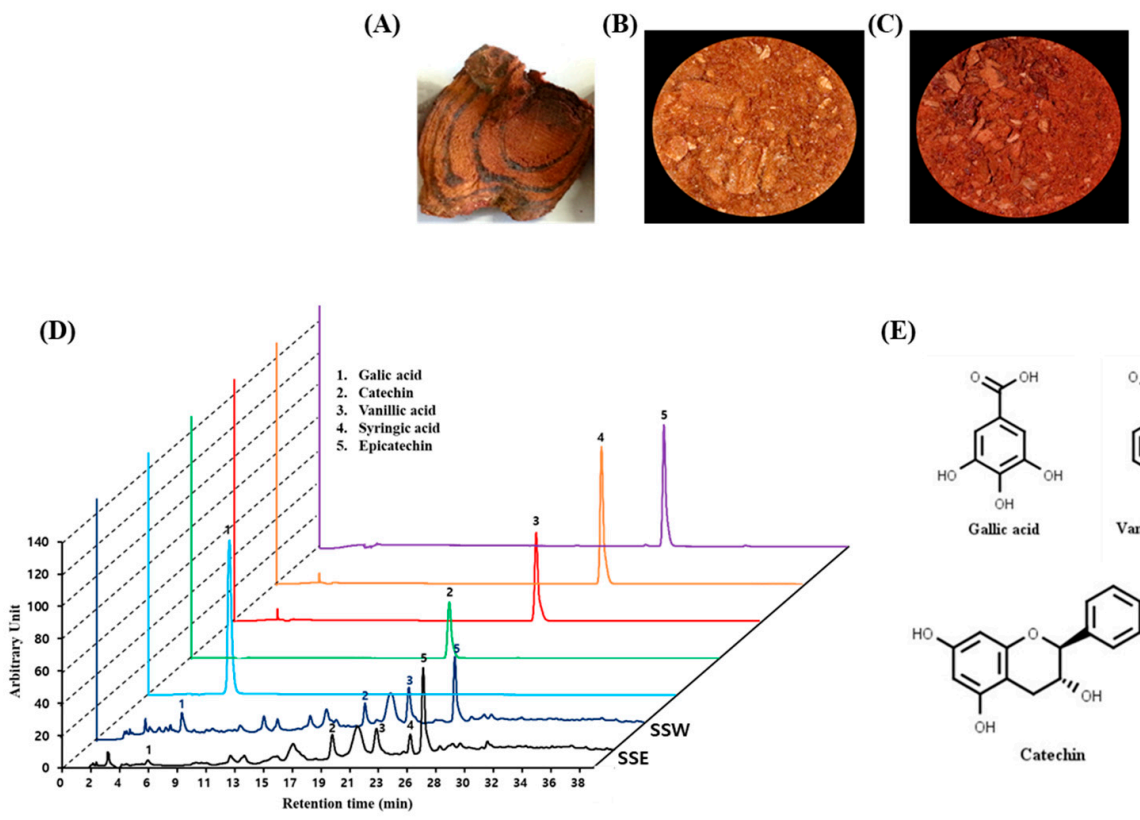

(E)

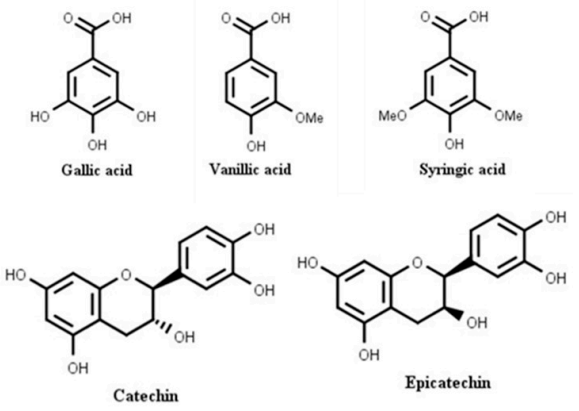

Figure 1. Classical feature of Sapatholobus suberectus (SS) and identification of ingredients. (A) Stem of Sapatholobus suberectus. (B,C) Powder of Sapatholobus suberectus stem's aqueous (SSW) and ethanolic (SSE) extracts. (D) high-performance liquid chromatography (HPLC) profile of the stem of Spatholobus suberectus. (E) Molecular structure of the 5 compounds identified, gallic acid (1); catechin (2); vanillic acid (3); syringic acid (4); and epicatechin (5).

\section{Materials and Methods}

\subsection{Plant Materials and Preparation of Plant Extracts}

The stem of Spatholobus suberectus (SS) was purchased from a Chinese medicinal herb shop in Zhengzhou, China (Figure 1A). The sample was dried at $30{ }^{\circ} \mathrm{C}$ for two days and then pulverized into a fine powder. Ten grams of coarsely dried powder was extracted three times using $100 \%$ ethanol and distilled water under reflux for $3 \mathrm{~h}$. The extract was decanted using filter paper (Whatman No. 1, Schleicher \& Schuell, Keene, NH, USA). Then, the solvent was removed and dried using a rotary vacuum evaporator (Tokyo Rikakikai Co. Ltd., Tokyo, Japan) and finally pulverized after freeze-drying (Ilshin Biobase, Goyang, Korea) the aqueous and ethanolic extract of SS (SSW and SSE, respectively) (Figure 1B,C, respectively). Powdered extracts were dissolved in distilled water and stored at $4{ }^{\circ} \mathrm{C}$ until testing.

\subsection{High-Performance Liquid Chromatography (HPLC) Analysis}

The phytochemical characteristics of SSW and SSE were analyzed by high-performance liquid chromatography (HPLC) using standard compounds such as catechin, (-)-epigallocatechin gallate (EGCG, E4268, Sigma-Aldrich), epicatechin, gallic acid, syringic acid, and vanillic acid. The HPLC analysis was performed using a Shimadzu Prominence Auto Sampler (SIL-20A) HPLC system (Shimadzu, Kyoto, Japan), equipped with an SPD-M20A diode array detector (PDA) and LC solution 1.22 SP1 software. Before analysis, the samples were filtered through a $0.2 \mu \mathrm{m}$ syringe filter (Pall Life Sciences, Ann Arbor, MI, USA). The reverse-phase chromatographic analysis was carried out using a Phenomenex C18 column $(4.6 \mathrm{~mm} \times 250 \mathrm{~mm})$ packed with $5 \mu \mathrm{m}$ diameter particles and maintained at $25{ }^{\circ} \mathrm{C}$. A stepwise gradient of solvent $\mathrm{A}$ to $\mathrm{B}$ was used (A: $2 \%$ acetic acid and B: $50 \%$ acetonitrile (ACN) in $0.5 \%$ acetic acid) according to a previous report [24] with a slight modification. The flow rate was $1 \mathrm{~mL} / \mathrm{min}$, and $10 \mu \mathrm{L}$ was injected. 


\subsection{Elastase Inhibition Assay and Combination Index}

The elastase inhibition assay was performed according to a previously reported method with minor modifications [25]. Briefly, the reaction was carried out in a $0.1 \mathrm{M}$ Tris- $\mathrm{HCl}$ buffer ( $\mathrm{pH}$ 8.0) containing $0.78 \mathrm{mM}$ N-Succinyl-(Ala)-3-p-nitroanilide (Sigma-Aldrich, St. Louis, MO, USA) as a substrate and $0.04 \mathrm{U}$ elastase (Sigma-Aldrich, St. Louis, MO, USA). EGCG was used as a positive control. A predetermined concentration $(10,30,100$, or $300 \mu \mathrm{g} / \mathrm{mL})$ of each sample was mixed thoroughly with $100 \mu \mathrm{L}$ of the substrate solution and consequently $100 \mu \mathrm{L}$ of the enzyme solution was added, and the absorbance was measured at $405 \mathrm{~nm}$ in a microplate reader (Wallac Victor3 1420 Multilabel Counter, Perkin Elmer, Waltham, MA, USA). The mode of interaction between syringic acid (SA), epicatechin (EP) and vanillic acid (VA) in inhibiting elastase was further analyzed by the CompuSyn program (ComboSyn Inc, Paramus, NJ, USA), which applies median effect equation methods. The combined drug effect is expressed as combination index $(\mathrm{CI})$ versus fraction affected $(\mathrm{Fa})$, with $\mathrm{CI}<1$ indicating synergism, $\mathrm{CI}=1$ indicating an additive effect, and $\mathrm{CI}>1$ indicating antagonism [26]. The CI values were calculated by the Chou-Talalay method based on the median-effect equation and the classic isobologram equation [26] using CompuSyn software (ComboSyn Inc, Paramus, NJ, USA).

\subsection{Cell Culture, UVB-Irradiation and Cell Viability Assay}

Human keratinocyte (HaCaT) cells were purchased from AddexBio Technologies (San Diego, CA, USA). Cells were grown in Dulbecco's modified Eagle's medium (DMEM) (Hyclone, Logan, UT, USA) supplemented with 10\% fetal bovine serum (FBS) (Hyclone, Mordialloc, Victoria, Australia) and 1\% penicillin-streptomycin (P/S) (Sigma-Aldrich, St. Louis, MO, USA) at $37^{\circ} \mathrm{C}$ in a humidified atmosphere containing $5 \% \mathrm{CO}_{2}$. Then, sub-confluent cells were treated with indicated concentration of SSW and SSE for $24 \mathrm{~h}$. Subsequently, the cells were exposed to UVB at a dose of $40 \mathrm{~mJ} / \mathrm{cm}^{2}$ using a UVB source (Bio-Link Crosslinker, Vilber Lourmat, Cedex, France) set at a spectral peak of $312 \mathrm{~nm}$ for $20 \mathrm{~s}$. Rigel et al. reported healthy high school volunteers daily received the UVB irradiation by $8.01 \mathrm{~mJ} / \mathrm{cm}^{2} /$ day [27]. In this experiment, we used UVB radiation at $40 \mathrm{~mJ} / \mathrm{cm}^{2}$, which is equivalent to approximately 5 days of sun exposure. After UVB irradiation, the cells were cultured in serum-free medium for $24 \mathrm{~h}$. Cell viability was determined using the 3- (4,5-dimethylthiazol-2-yl) -2,5-diphenyltetrazolium bromide (MTT) colorimetric assay as described previously [28].

\subsection{ROS Generation Assay}

Intracellular ROS production in cells was detected using $2^{\prime}, 7^{\prime}$-Dichlorofluorescein diacetate (DCFH-DA) (Sigma-Aldrich, St. Louis, MO, USA) according to the methods described previously [26]. Cells were grown to $70-80 \%$ confluence then cultured $\left(1 \times 10^{5}\right.$ cells $\left./ \mathrm{mL}\right)$ with indicated concentration of SSW and SSE in 96-well black clear bottomed plates (Corning Inc., Corning, NY, USA) for $24 \mathrm{~h}$ and then exposed to UVB-irradiation $\left(40 \mathrm{~mJ} / \mathrm{cm}^{2}\right)$, and further incubated for $24 \mathrm{~h}$. Then, the cells were washed with phosphate-buffered saline (PBS) twice and treated with DCFH-DA ( $25 \mu \mathrm{M})$ for $30 \mathrm{~min}$. Finally, fluorescence intensity was measured at excitation and emission wavelengths of 485 and 528 $\mathrm{nm}$, respectively, by a fluorescence microplate reader (Victor3, PerkinElmer, Waltham, MA, USA).

\subsection{RNA Extraction and Reverse Transcription-Polymerase Chain Reaction (RT-PCR)}

HaCaT cells $\left(1 \times 10^{5}\right.$ cells $\left./ \mathrm{mL}\right)$ were cultured with indicated concentration of SSW and SSE (f.c. 3, 10, or $30 \mu \mathrm{g} / \mathrm{mL}$ ) in 6-well plates for $24 \mathrm{~h}$. Total RNA was isolated using TRIzol (Invitrogen, Carlsbad, CA, USA) following the manufacturer's instructions. $2 \mu \mathrm{g}$ of total RNA was used to prepare the complementary DNA (cDNA) using RT \& GO Mastermix (MP Biomedicals, Seoul, Korea). A polymerase chain reaction (PCR) Thermal Cycler Dice TP600 (Takara Bio Inc., Otsu, Japan) was used to carry out RT-PCR using the various primer sequences (Table S1), according to the methods described earlier [28]. 


\subsection{Preparation of Protein Lysates and Western Blotting}

The lysates of $\mathrm{HaCaT}$ cells $\left(2 \times 10^{5}\right.$ cells/mL) were prepared using radioimmunoprecipitation assay (RIPA) buffer with a phosphatase and protease inhibitor cocktail (Sigma-Aldrich, St. Louis, $\mathrm{MO}, \mathrm{USA}$ ) and the bicinchoninic acid (BCA) method was applied to quantify the protein content. A nuclear/cytosolic fractionation kit (Sigma-Aldrich, St. Louis, MO, USA) was used for the extraction of nuclear proteins. Aliquots of $30 \mu \mathrm{g}$ of total proteins were used to carry out the Western blot analysis using various antibodies (Table S2) according to our previously described methods [28].

\subsection{Statistical Analysis}

The experimental data are presented as the mean \pm standard deviation (SD). Enzyme, cell viability data were analyzed using a paired Student's t-test. The statistical analysis of the rest of the data was carried out by one-way analysis of variance (ANOVA), followed by Dennett's test using the SigmaPlot 12.5 (Systat Software Inc., San Jose, CA, USA). Differences were considered significant when ${ }^{* *} p \leq 0.05$ or * $p \leq 0.01$.

\section{Results}

\subsection{HPLC Analysis of Stem of Spatholobus Suberectus (SS)}

To gain insight into the phytochemicals present in SS stem extract, HPLC analysis was performed with standard phenolic and flavonoid compounds. Interestingly, the aqueous and ethanolic extracts of SS stem (SSW and SSE, respectively) (Figure 1B,C) demonstrated several peaks, with the retention times to be harmonized in the following standard compounds: gallic acid (6.380 min), catechin (20.074 $\mathrm{min}$ ), vanillic acid (23.601 min), syringic acid (25.352 $\mathrm{min}$ ) and epicatechin (26.809 min) (Figure 1D).

By using the peak areas of known concentrations of standards, the amounts of these polyphenols in Spatholobus suberectus stem extract were determined. As shown in Figure 1D, SSW contains gallic acid $(6.90 \mu \mathrm{g} / \mathrm{mL})$, syringic acid $(27.08 \mu \mathrm{g} / \mathrm{mL})$ and epicatechin $(105.59 \mu \mathrm{g} / \mathrm{mL})$ while SSE contains gallic acid $(1.48 \mu \mathrm{g} / \mathrm{mL})$, vanillic acid $(21.07 \mu \mathrm{g} / \mathrm{mL})$, syringic acid $(28.23 \mu \mathrm{g} / \mathrm{mL})$, catechin $(1.86 \mu \mathrm{g} / \mathrm{mL})$, and epicatechin (142.17 $\mu \mathrm{g} / \mathrm{mL})$ (Figure 1D). Both extracts commonly found to contain gallic acid, catechin, syringic acid and epicatechin.

\subsection{Inhibition of Elastase Activity by SS Stem}

The elastase inhibition assay revealed both SSW and SSE were suppressed the elastase activity in a concentration-dependent manner (Figure 2A). At $100 \mu \mathrm{g} / \mathrm{mL}$, SSE showed 79\% inhibition of elastase activity whereas EGCG (used as positive control) and SSW had similar inhibitory activity as 59\%. The $\mathrm{IC}_{50}$ values of the elastase inhibition activity were in the order of SSE $>$ SSW $>$ EGCG. These results suggest that SSW and SSE were found to suppress the breakdown of elastin, which in combination with collagen contributes to skin wrinkles.

\subsection{The Effet of SS on Cell Viability of Human Keratinocytes (HaCaT) Cells}

Cell viability was determined using the MTT assay in HaCaT cells (Figure 2B). The cell viability of approximately $80 \%$ was considered to be non-toxic. SSW did not show any toxicity up to a concentration of $30 \mu \mathrm{g} / \mathrm{mL}$, but the survival rate was decreased to $68 \%$ at a concentration of $100 \mu \mathrm{g} / \mathrm{mL}$. On the other hand, SSE showed no cell toxicity up to $100 \mu \mathrm{g} / \mathrm{mL}$, but the survival rate was approximately $68 \%$ at a concentration of $300 \mu \mathrm{g} / \mathrm{mL}$. Therefore, $30 \mu \mathrm{g} / \mathrm{mL}$ was considered the highest concentration for the subsequent experiments for both samples.

To determine the UVB intensity to be used in the analysis, the survival rate of the cells was examined by irradiating them with UVB. Cells were irradiated with UVB at $0,30,40$, and $50 \mathrm{~mJ} / \mathrm{cm}^{2}$ for cytotoxicity according to UVB irradiation intensity. The survival rate of the HaCaT cells was about $86 \%$ at $30 \mathrm{~mJ} / \mathrm{cm}^{2}$ and $75 \%$ at $40 \mathrm{~mJ} / \mathrm{cm}^{2}$ (Figure S1). As shown in Figure 2C, UVB irradiation 
significantly reduced the cell viability, while pretreatment of both SSW and SSE alleviated the harmful effect of radiation to the cells. Upon UVB irradiation, the cell viability was reduced by $18 \%$ whereas pretreatment with both SSW and SSE restored the cell survivability. Surprisingly, at a concentration of $30 \mu \mathrm{g} / \mathrm{mL}$ of SSW and SSE, both extracts completely abolished the effects of UV-induced cell damage (Figure 2C).

(A)

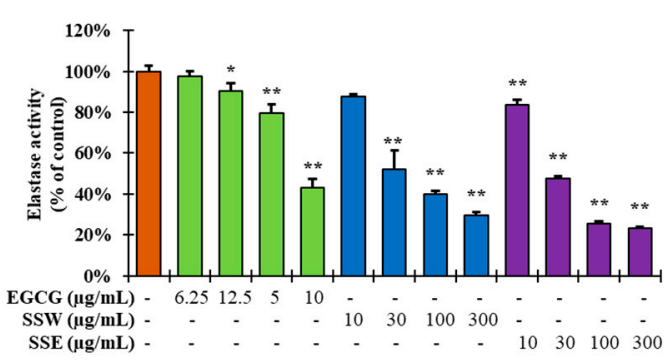

(C)

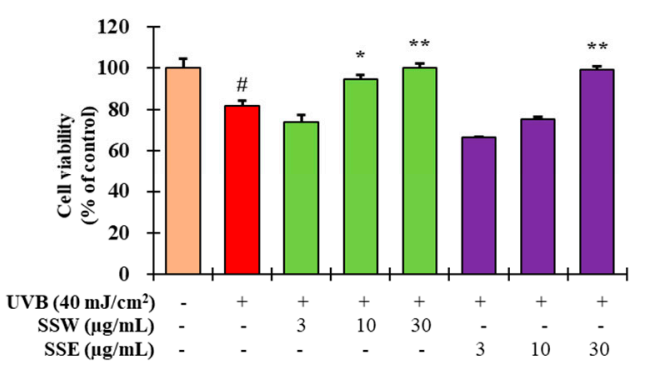

(B)

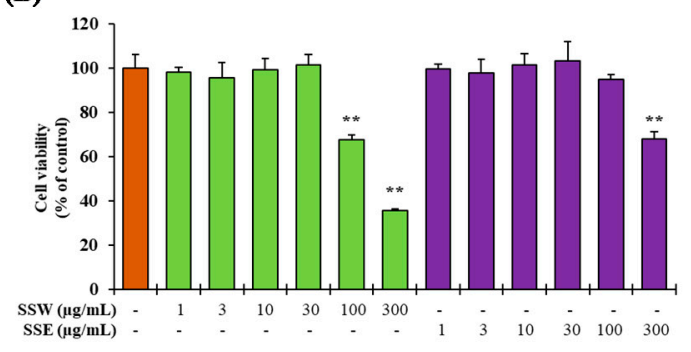

(D)

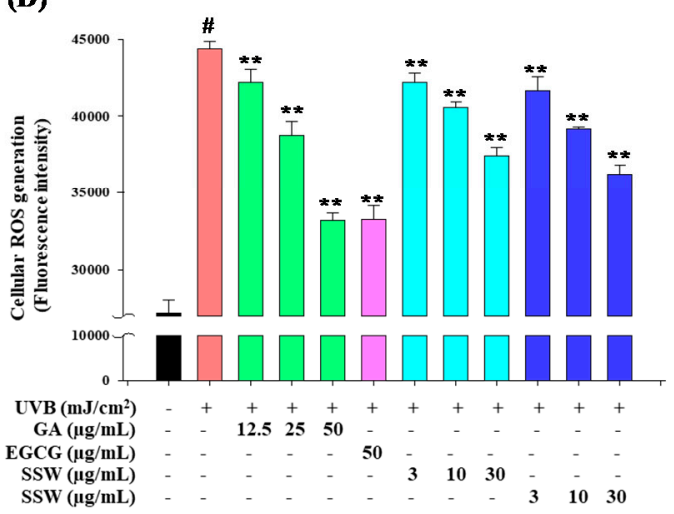

Figure 2. Comparison of anti-aging potential by SS. (A) Inhibitory effects of SS stem extracts on elastase activity. The results are denoted as the mean \pm standard deviation (SD) from triplicate experiments $\left({ }^{* *}\right.$ $p \leq 0.01,{ }^{*} p \leq 0.05$ compared with the control group). (B) Cytotoxicity of SS stem extracts in HaCaT cells. Cells $\left(1 \times 10^{5}\right.$ cells $\left./ \mathrm{mL}\right)$ were seeded in a 96-well plate and treated with aqueous and ethanolic extracts of SS stem (SSW and SSE) at 1, 3, 10, 30,100, and $300 \mu \mathrm{g} / \mathrm{mL}$. The cell viability was determined using 3- (4,5-dimethylthiazol-2-yl) -2,5-diphenyltetrazolium bromide (MTT) assay. (C) Phototoxicity of SS stem extracts in HaCaT cells. Cells $\left(1 \times 10^{5}\right.$ cells $\left./ \mathrm{mL}\right)$ were treated with SSW and SSE at 3, 10, or 30 $\mu \mathrm{g} / \mathrm{mL}$. After $24 \mathrm{~h}, \mathrm{UVB}\left(40 \mathrm{~mJ} / \mathrm{cm}^{2}\right)$ was irradiated and the cells were cultured in serum-free medium for $24 \mathrm{~h}$. The cell viability was measured using the MTT assay. The data are denoted as the mean \pm SD from triplicate results. (\# $p \leq 0.01$, compared with the non treated control (NT); ${ }^{* *} p \leq 0.01,{ }^{*} p \leq$ 0.05 compared with the UV control group). (D) Reactive oxygen species (ROS) generation activity was measured using $\mathrm{HaCaT}$ cells according to the method described in materials and methods. EGCG: (-)-epigallocatechin gallate; GA: gallic acid.

\subsection{Suppression of UVB-Stimulated Reactive Oxygen Species (ROS) Generation by SS}

The goal was to investigate whether SSW and SSE suppress the UVB-stimulated ROS production. As described in Figure 2D, UVB irradiation significantly enhanced ROS generation compared with the non-irradiated cells. Pretreatment of SSW and SSE significantly lessened ROS generation compared with the UV-irradiated control. At a concentration of $30 \mu \mathrm{g} / \mathrm{mL}$, both SSW and SSE decreased ROS production about $11 \%$ and $18 \%$, respectively. On the other hand, both gallic acid and EGCG suppressed almost $50 \%$ of UVB stimulated ROS generation at $50 \mu \mathrm{g} / \mathrm{mL}$. 


\subsection{Regulation of UVB-Induced Matrix Metalloproteinases (MMPS) Expression by SS}

In order to confirm the capability of SSE to regulate UVB-stimulated MMPs expression, HaCaT cells were pretreated by SSE followed by subjected to expose in UVB $\left(40 \mathrm{~mJ} / \mathrm{cm}^{2}\right)$, and the expression of MMPs was determined by RT-PCR and immunoblotting assay. As described in Figure 3A,B, pretreatment of SSE significantly abolished the UVB-stimulated MMPs mRNA level in a dose-dependent fashion. Interestingly, the suppressive effect of SSE on MMP-1 and -2 expression was higher than that of EGCG used as a positive control (Figure 3B). Furthermore, the results show that pretreatment with both SSW and SSE was significantly reduced in UV-induced MMP-12 transcriptional levels in a concentration-dependent fashion (Figure 3A).

(A)

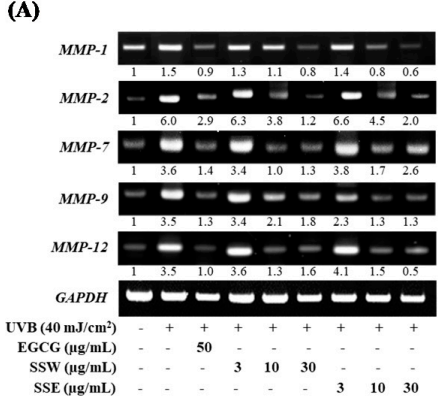

(B)

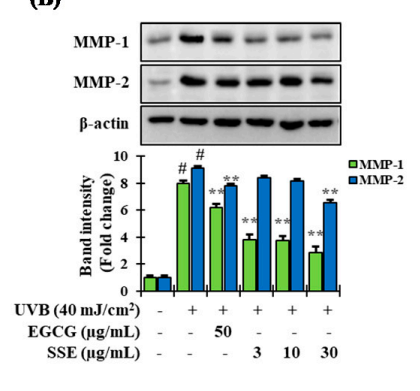

(C)

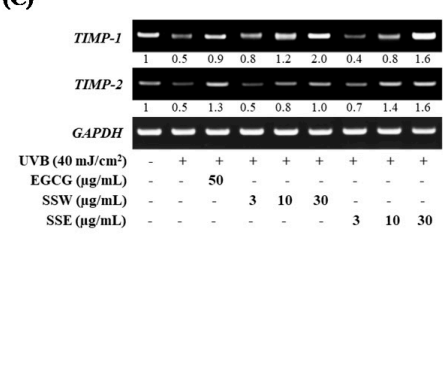

(D)

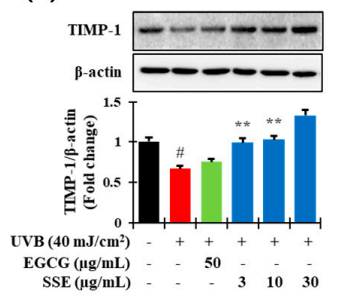

(E)

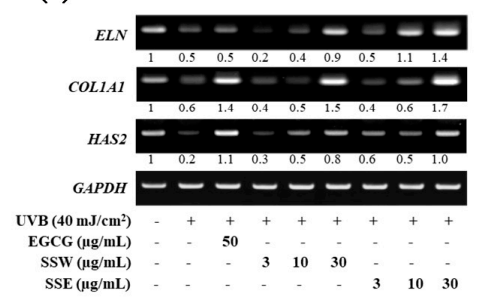

(F)

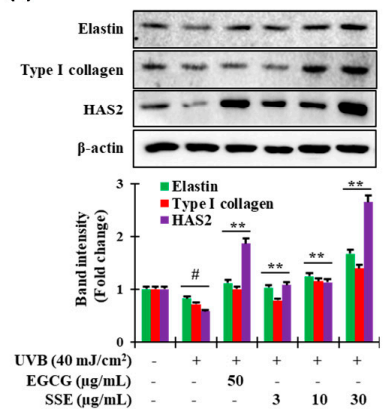

Figure 3. Effects of aging-related biomarkers by SSE. The effects of SSE on the regulation of (A) the mRNA expression and (B) the protein level of MMPs; $(\mathbf{C})$ the mRNA expression and (D) the protein level of tissue inhibitors of matrix metalloproteinases (TIMPs); (E) the mRNA expression and (F) the protein level of elastin (ELN), type I collagen (COL1A1) and hyaluronan synthase 2 (HAS2) induced by $\mathrm{UVB}\left(40 \mathrm{~mJ} / \mathrm{cm}^{2}\right)$ in $\mathrm{HaCaT}$ cells. Cells were cultured for $24 \mathrm{~h}$, and then with the indicated concentration of SSW and SSE for further $12 \mathrm{~h}$. Then the cells were irradiated with $40 \mathrm{~mJ} / \mathrm{cm}^{2} \mathrm{UVB}$ and cultured for additional $12 \mathrm{~h}$. Reverse transcription-polymerase chain reaction (RT-PCR) and western blot was carried out according to the methods described in materials and methods. The data are denoted as the mean \pm SD from triplicate results. (\# $p \leq 0.01$, compared with the NT; ${ }^{* *} p \leq 0.05$, compared with the ultraviolet (UV) control group). EGCG: (-)-epigallocatechin gallate used as a positive control.

Furthermore, to confirm whether SSE could regulate the TIMPs expression in UVB-stimulated $\mathrm{HaCaT}$ cells, both RT-PCR and western blotting assay were carried out. As described in Figure 3C,D, UVB treatment downregulated the TIMP expression compared to non-treated cells, while SSE pretreatment further halted this action.

\subsection{Effects of SSE on the Expression of COL1A1, ELN and HAS2}

Skin wrinkles and elasticity are mainly influenced by collagen, elastin, and hyaluronic acid. Therefore, to examine whether the SS stem extracts had the ability to regulate these biomarkers, the transcriptional and translational expression of elastin (ELN), type I collagen (COL1A1) and hyaluronan synthase 2 (HAS2) was confirmed by RT-PCR and immunoblotting, respectively (Figure 3E,F). The 
results show that UVB treatment drastically downregulated the transcriptional and translational level of elastin, type I collagen, and hyaluronan synthase 2, while pretreatment of SSE fixed their expression.

\subsection{Downregulation of NF- $\kappa B$ and AP-1 by SSE}

It is well known that the transcriptional levels of various MMPs are strongly modulated by NF- $\kappa B$ and AP-1. They also play significant roles in maintaining the ECM composition as well as in cytokine expression [29]. Because SSE stifled the expression of MMPs, we next examined whether SSE was able to regulate the transcription factors of NF- $\mathrm{KB}$ and AP-1 which is responsible for MMPs expression. To estimate the modifications of the expressions of NF- $\mathrm{KB}$ and AP-1 transcription factors induced by SSE in UVB-treated HaCaT cells, we turned to immunoblotting. The protein levels of NF- $\mathrm{kB}$ family members, p65, were significantly raised by UVB but lessened by SSE in a concentration dependent fashion (Figure 4A, upper layer). Likewise, SSE also considerably reduced the protein levels of p-c-Jun, which are the components of AP-1 (Figure 4A, lower layer).
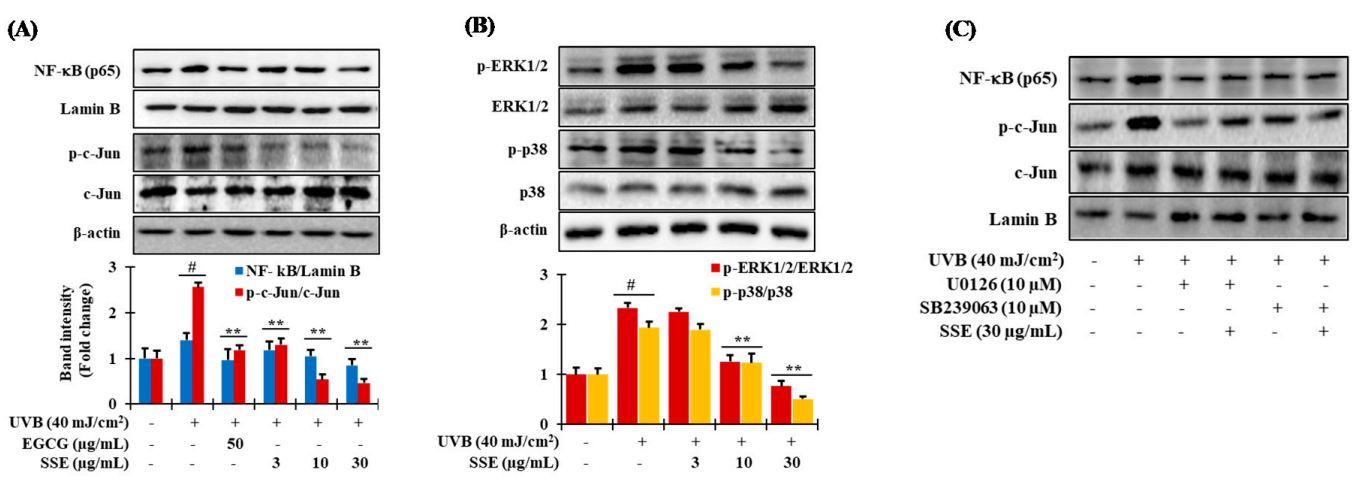

Figure 4. Modulation of mitogen-activated protein kinase (MAPK)/nuclear factor-kappa B (NF- $\mathrm{B}$ ) and AP-1 signaling by SSE in UVB-stimulated HaCaT cells. (A) The effect of SSE on the phosphorylation of NF- $\mathrm{B}$, p-c-Jun and c-Jun modulated by UVB. Cells were cultured for $24 \mathrm{~h}$, and then SSE were added for $12 \mathrm{~h}$. After that, UVB was irradiated at $40 \mathrm{~mJ} / \mathrm{cm}^{2}$, and the protein expression was confirmed by western blot as described in materials and methods. (B) The effects of SSE on the phosphorylation of mitogen-activated protein (MAP) kinase activated by UVB. A $12 \mathrm{~h}$ pretreated cells by SSE, UVB was irradiated at $40 \mathrm{~mJ} / \mathrm{cm}^{2}$, and the protein was extracted after $30 \mathrm{~min}$. Protein expression was confirmed by western blot. (C) Specific extracellular signal-regulated kinases (ERK) and p38 inhibitors (U0126 and SB239063, respectively) manifest the effects of SSE on the regulation of NF- $\mathrm{KB}$ and AP-1 expression in UVB-irradiated HaCaT cells. Cell were treated according to the above-mentioned protocol and protein expression was evaluated by immunoblotting. (\# $p \leq 0.05$, compared with the NT; ${ }^{* *} p \leq 0.05$, compared with the ultraviolet (UV) control group). EGCG: (-)-epigallocatechin gallate.

\subsection{Effects of SSE on the Phosphorylation of Mitogen-Activated Protein Kinase (MAPK) Proteins}

Next, we investigated the pathway through which SSE exhibits its anti-photoaging effects. Generally, UVB induced augmented ROS production leads to the activation of MAPK proteins including extracellular signal-regulated kinases (ERK), p38 mitogen-activated protein kinases (p38) and c-Jun $\mathrm{N}$-terminal kinases (JNK). MAPK induces NF- $\mathrm{KB}$ and AP-1 which consequently boosts the expression of MMPs, lead to decrease of collagen and other ECM in aged skin [30]. To investigate the effects of SSE on UVB-induced photoaging, the phosphorylation of MAPKs was assessed. UVB-irradiation significantly amplified the phosphorylation of ERK, and p38, compared with non-irradiated cells and peak at 30 min after UVB exposure (Figure S2), while the phosphorylation of JNK was minimal. Our data are consistent with studies by Chouinard et al. where it was shown that UVB failed to activate JNK, albeit the induction was more pronounced for the phosphorylation of ERK1/2 and p38 [31]. Treatment with SSE at $30 \mu \mathrm{g} / \mathrm{mL}$ provided the most inhibition on phosphorylated ERK1/2 and p38 (Figure 4B) whereas the inhibition effects of SSE on the phosphorylation of JNK was absent. Thus, to validate whether SSE-modulated downregulation of NF- $\mathrm{KB}$ and AP-1 is associated with the MAPK 
signaling cascade, cells were treated with specific p38 and ERK1/2 inhibitors, such as SB239063 and U0126, respectively, before being treated with SSE. Both p38 and ERK1/2 inhibition, along with SSE, exhibited the potential to attenuate the protein expression of NF- $\mathrm{kB}$ and AP-1 (Figure 4C). These data show that the suppression of UVB-stimulated ERK and p38 phosphorylation by SSE are required in the attenuation of NF-KB and AP-1 in HaCaT cells.

\subsection{Combination Studies of the Major Components of SSE on Elastase Inhibition Activity}

The major compounds of SSE identified were syringic acid (SA), epicatechin (EP) and vanillic acid (VA), and all of them showed dose-dependent moderate elastase inhibitory activity (Figure 5A). These results suggest that SA, EP and VA could inhibit elastase activity by different pathways and that combination of these agents might result in boosted inhibitory effects. Thus, we compared the inhibitory potencies of SA, EP and VA and their combinations (SA and EP; VA and EP, SA and VA at 1:9, 1:4, 1:2 and 1:1 ratio as well as SA, VA and EP at 1:1:1, 2:1:1, 1:2:1 and 1:1:2 ratio) on elastase inhibition activity. Combinations of equimolar doses of SA and EP showed nearly additive effects $(C I=0.97)$ while other all combination doses showed slight antagonism (Figure 5B). As described in Figure 5C, VA and EP combinations also showed nearly additive effects in all combinations (CI $=0.99$, 0.91 and 0.99 at 1:4, 1:2 and 1:1 ratio, respectively) except 1:9 (VA:EP) ratio. These results suggested that the lower concentration of EP showed additive effects by combining with SA and/or VA. Moreover, combination of SA and VA at 1:2, 1:1, and 2:1 ratio showed very good synergistic effects $(\mathrm{CI}=0.41,0.22$ and 0.37 , respectively) on elastase inhibition (Figure 5D). Furthermore, strong synergism was observed at 2:1:1 molar ratio of SA, VA and EP $(\mathrm{CI}=0.28)$, while other combinations of these three compounds also gave a moderate synergism effect (Figure 5E). Our experiments demonstrated that only lower concentrations of EP with SA and/or VA had additive effects, while combination of SA, VA and EP at lower concentrations was potently synergistic.

(A)

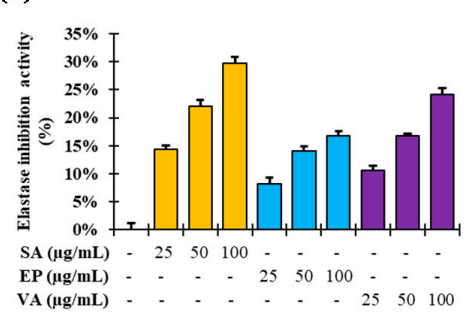

(D)

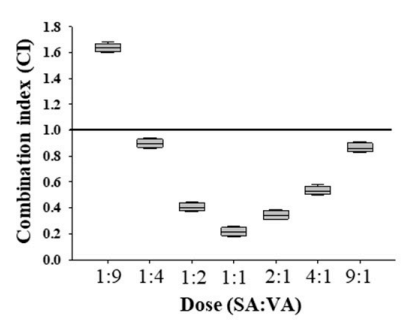

(B)

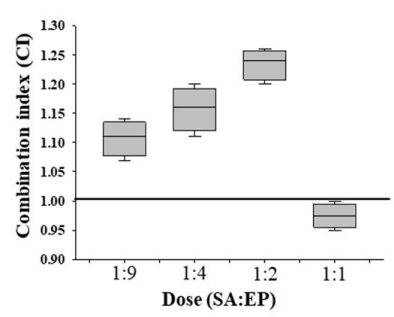

(E)

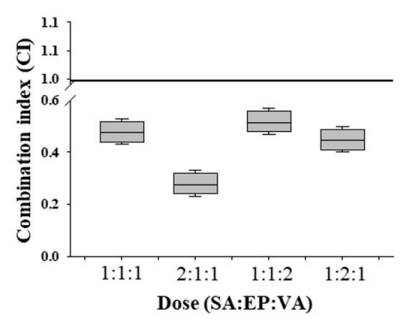

(C)

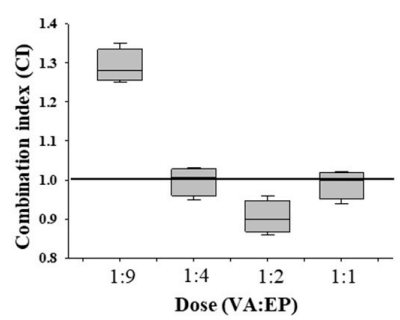

Figure 5. Individual and combination effects of elastase inhibition by the major identified compounds of SSE. (A) Elastase inhibition activity of the major identified compounds of SSE. The results are denoted as the mean \pm SD from triplicate experiments. (B-E) Combination effects of elastase inhibition by the major identified compounds of SSE. Combination index (CI) values of $<1,=1$, and $>1$ indicate synergism, additive effect, and antagonism, respectively. CI values shown are mean $\pm \mathrm{SE}$ with a minimum of three experiments. SA: syringic acid; EP: epicatechin and VA: vanillic acid. The raw compuSyn report are given in supplementary data. 


\section{Discussion}

Epidemiological studies revealed that overexposure of UV irradiation significantly increases the magnitude of patients with skin damage. Chronical exposure of UV irradiation to skin causes oxidative stress, inflammation, ROS-mediated DNA damage, and disorder of cellular signaling pathways, resulting in accelerated skin photo-aging [32,33]. Botanicals possessing antioxidant, anti-inflammatory and immunomodulatory properties are promising to be exploited as therapeutic agents for a variety of skin disorders, including photo-aging [34,35]. Spatholobus suberectus (SS) stem was found to contain various polyphenolics, such as gallic acid, vanillic acid (VA), epicatechin (EP), and syringic acid (SA) (Figure 1D). Among them, gallic acid has been reported to be effective for anti-aging in human fibroblasts through wound healing [36], and syringic acid has been reported to be effective for elastase inhibition [37]. Indeed, various photochemopreventive agents derived from dietary origin have shown the potential efficacy on skin delivery through oral systemic administration, an emerging concept referred to as 'nutritional' or 'systemic photoprotection'. The systemic administration of an apocarotenoid bixin, an FDA-approved natural food colorant from the seeds of the achiote tree (Bixa orellana), protect the solar UV-induced skin damage in SKH-1 mice through the activation of cutaneous Nrf-2 signaling [38]. In this study, the aqueous and ethanolic extracts of SS stem's (SSW and SSE, respectively) significantly inhibited elastase activity (Figure 2A), possibly due to the presence of SA, VA and EP, which may cause synergism on elastase inhibition (Figure 5). Furthermore, HaCaT cells, which are human epidermal keratinocytes, were considered to prove the underlining mechanism of the anti-photoaging activity of SSE. Before experimentation, the toxicity of the extracts to the cells was confirmed. Both SSW and SSE were found to be non-toxic in HaCaT cells up to a concentration of $30 \mu \mathrm{g} / \mathrm{mL}$ (Figure 2B). Therefore, the following concentrations were used in subsequent experiments.

MMPs play an important role in the physiological mechanisms of skin photo-aging. UV irradiation alters the connective tissues of the skin by up-regulating the expression of MMPs, which degrade collagen and other ECM proteins. SSE has been shown to suppress UVB-induced upregulation of MMP-1 and -2 (Figure 3A,B). MMP-1 is a major collagenase that causes collagen degradation in skin severely damaged by UV. MMP-12 is the most important elastin-degrading enzyme and is involved with elastin and many other substrates, such as ECM collagen [39]. The tissue inhibitors of metalloproteinases or TIMPs suppress MMP activity critical for extracellular matrix turnover associated with both physiologic and pathologic tissue remodeling. TIMP concentrations generally far exceed the concentration of MMPs in tissue and extracellular fluids, thereby limiting their proteolytic activity to focal pericellular sites [40]. Treatment of SSE significantly boosted the TIMP-1 and -2 expression than that of UVB-stimulated cells (Figure 3C,D)

Notably, collagen is the principal protein that connects skin tissue, and the decomposition of collagen produces wrinkles in the skin. COL1A1 is one of the genes that constitute type I collagen and decreases upon exposure of UV [5,6]. Elastin is an extracellular matrix protein that binds to collagen and provides elasticity to the skin or elastic tissue. It is reduced by the activation of elastase upon UVB exposure [41]. When collagen and elastin are combined, hyaluronic acid plays a supporting role. Hyaluronan synthase 2 (HAS2) is an enzyme that synthesizes hyaluronic acid and plays a role in supporting the structure of the skin. In addition, HAS2 is abolished upon UVB skin irradiation [42]. SSE treatment significantly hindered the UVB-induced downregulation of type I collagen, elastin and HAS2 expression in concentration dependent manner (Figure 3E,F), which also supports the result that treatment with SSE increases cell proliferation.

UV irradiation stimulates cell surface growth factor receptors, cytokines, and MAPKs, which in turn regulate AP-1. Increased AP-1 activity down-regulates type I pro-collagen and up-regulates MMP-1. MMP-1 gene expression is regulated by c-Jun and c-Fos, which are components of the AP-1 heterodimer complex [33]. Moreover, it has been well established that a transcription factor, nuclear factor $\mathrm{\kappa B}(\mathrm{NF}-\mathrm{kB})$, is activated in skin keratinocytes by UV irradiation and leads to the augmentation of the levels of MMP-1, thus suppression of NF- $k B$ pathway would freeze the UVB-induced skin photoaging process [43]. Interestingly, SSE treatment significantly suppressed UV-induced c-Jun 
expression (Figure 4B), which may inhibit AP-1 activity as well as NF- $\mathrm{kB}$ signaling cascade resulting in suppression of MMPs expression. Our results are also in accordance with the previous studies [44], in which the active parthenolide, a sesquiterpene lactone compound of Tanacetum parthenium, completely blocked the NF-KB signaling pathway and hindered the UVB-mediated cutaneous alteration in both cultured cell and animal model. Furthermore, Terminalia catappa water extract protected skin from photodamage by inhibiting the MAPK/AP-1/MMP pathway [45]. Cumulating evidence has shown that exposure of the skin to UV induces ROS generation triggers MAPKs (ERK, JNK, and p38) phosphorylation, NF- $\mathrm{kB}, \mathrm{AP}-1$ activation, and regulates the expression of genes and proteins such as MMPs, leading to collagen degradation, resulting in photodamage and photo-carcinogenesis [41,43]. In the present study, UVB stimulation upregulated the phosphorylation of MAPKs, AP-1, NF- $\mathrm{KB}$ and MMPs, while SSE significantly suppressed these effects (Figure 4). Pharmacological inhibition of these signaling cascades abolished SSE-induced nuclear accumulation of AP-1, and NF- $\mathrm{kB}$ (Figure 4C). This finding suggests that SSE activity is dependent on this signaling transduction. The possible mechanisms of action of the Spatholobus suberectus stem extract against skin photoaging are summarized in Figure 6.

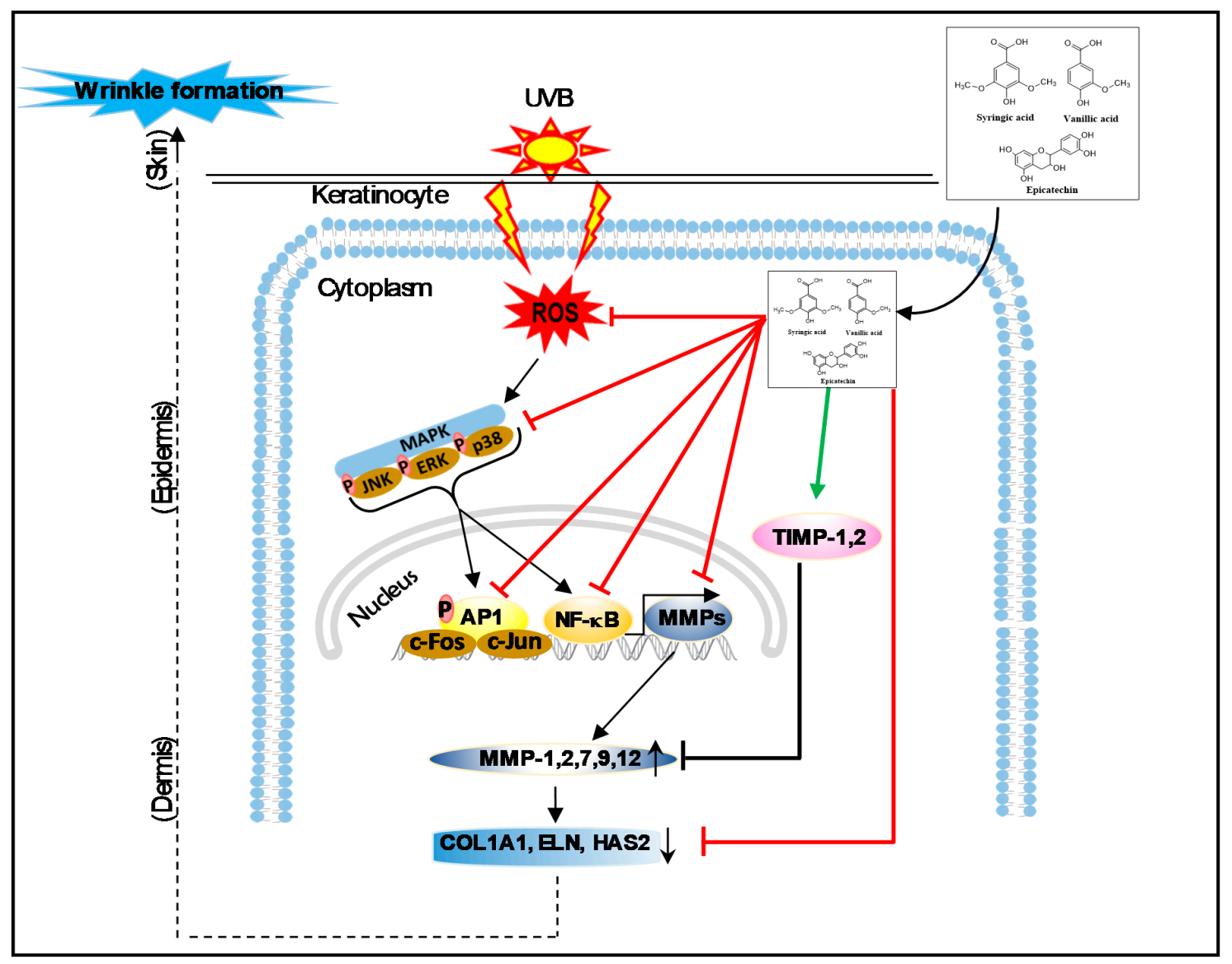

Figure 6. A proposed mechanism of SSE against UVB-induced photo-aging.

\section{Conclusions}

In this study, SS stem extract inhibited the ROS production by UV as well as repressing UV-activated MAP kinase, and ultimately enhanced the expression of COL1A1, ELN and HAS2. The active components, which were identified by HPLC as gallic acid, catechin, vanillic acid, syringic acid, and epicatechin, not only affect protection from ROS and cellular damage, but also inhibition of MMPs, activation of COL1A1, ELN, and HAS2, eventually blocking the phosphorylation of MAPKs and its downstream transcription factor such as AP-1, and NF- $\mathrm{kB}$. These results collectively suggest that 
Spatholobus suberectus stem extract seems to be valuable as a natural biomaterial that can inhibit UVB-stimulated photo-aging.

Supplementary Materials: The following are available online at http://www.mdpi.com/2072-6643/11/6/1341/s1, Figure S1: Cell viability UVB-irradiation. HaCaT cells $(1 \times 105$ cells $/ \mathrm{mL})$ were seeded in a 96-well plate and treated with UVB-irradiation at 20,30, 40 and $50 \mathrm{~mJ} / \mathrm{cm}^{2}$. The cell viability was determined using the MTT assay, Figure S2: The effects of UVB-irradiation on the phosphorylation of MAP kinase in HaCaT cells. HaCaT cells $(1 \times 105$ cells $/ \mathrm{mL})$ were seeded in a 6-well plate and treated with UVBirradiation at $40 \mathrm{~mJ} / \mathrm{cm}^{2}$ and the protein was extracted after 15, 30, 60 and 120 min Protein expression was confirmed by western blot, Table S1: List of the primer sets used in this study, Table S2: List of antibodies used in this study.

Author Contributions: K.-R.K. and J.-H.P. performed the experiments. K.-R.K., M.B.A., J.-H.P., T.-H.K. and S.-H.L. designed the research and analyzed the data. K.-R.K., M.B.A. and S.-H.L. wrote the paper. M.B.A. and S.-H.L. revised the paper.

Funding: This research received no external funding.

Acknowledgments: Md Badrul Alam and Ji-Hyun Park are supported by BK21Plus Creative Innovative Group for Leading Future Functional Food Industry, Kyungpook National University.

Conflicts of Interest: The authors declare that there was no conflict of interest.

\section{References}

1. Kammeyer, A.; Luiten, R.M. Oxidation events and skin aging. Ageing Res. Rev. 2015, 21, 16-29. [CrossRef] [PubMed]

2. Cela, E.M.; Friedrich, A.; Paz, M.L.; Vanzulli, S.I.; Leoni, J.; Gonzalez Maglio, D.H. Time-course study of different innate immune mediators produced by UV-irradiated skin: Comparative effects of short and daily versus a single harmful UV exposure. Immunology 2015, 145, 82-93. [CrossRef] [PubMed]

3. Lawrence, K.P.; Douki, T.; Sarkany, R.P.E.; Acker, S.; Herzog, B.; Young, A.R. The UV/visible radiation boundary region (385-405 $\mathrm{nm}$ ) damages skin cells and induces "dark" cyclobutane pyrimidine dimers in human skin in vivo. Sci. Rep. 2018, 8, 12722. [CrossRef] [PubMed]

4. Tewari, A.; Grys, K.; Kollet, J.; Sarkany, R.; Young, A.R. Upregulation of MMP12 and its activity by UVA1 in human skin: Potential implications for photoaging. J. Investig. Dermatol. 2014, 134, 2598-2609. [CrossRef] [PubMed]

5. Varani, J.; Spearman, D.; Perone, P.; Fligiel, S.E.; Datta, S.C.; Wang, Z.Q.; Shao, Y.; Kang, S.; Fisher, G.J.; Voorhees, J.J. Inhibition of type I procollagen synthesis by damaged collagen in photoaged skin and by collagenase-degraded collagen in vitro. Am. J. Pathol. 2001, 158, 931-942. [CrossRef]

6. Catania, J.M.; Chen, G.; Parrish, A.R. Role of matrix metalloproteinases in renal pathophysiologies. Am. J. Physiol. Ren. Physiol. 2007, 292, F905-F911. [CrossRef]

7. Woessner, J.F. Matrix metalloproteinases and their inhibitors in connective tissue remodeling. FASEB J. 1991, 5, 2145-2154. [CrossRef]

8. Wlaschek, M.; Tantcheva-Poor, I.; Naderi, L.; Ma, W.; Schneider, L.A.; Razi-Wolf, Z.; Schuller, J.; Scharffetter-Kochanek, K. Solar UV irradiation and dermal photoaging. J. Photochem. Photobiol. B Biol. 2001, 63, 41-51. [CrossRef]

9. Fisher, G.J.; Datta, S.C.; Talwar, H.S.; Wang, Z.Q.; Varani, J.; Kang, S.; Voorhees, J.J. Molecular basis of sun-induced premature skin ageing and retinoid antagonism. Nature 1996, 379, 335-339. [CrossRef]

10. Kim, H.S.; Park, W.S.; Baek, J.I.; Lee, B.S.; Yoo, D.S.; Park, S.J. Continuous irradiation with a 633-nm light-emitting diode exerts an anti-aging effect on human skin cells. Int. J. Mol. Med. 2015, 35, 383-390. [CrossRef]

11. Weston, C.R.; Davis, R.J. The JNK signal transduction pathway. Curr. Opin. Genet. Dev. 2002, 12, $14-21$. [CrossRef]

12. Anggakusuma; Yanti; Hwang, J.K. Effects of macelignan isolated from Myristica fragrans Houtt. on UVB-induced matrix metalloproteinase-9 and cyclooxygenase-2 in HaCaT cells. J. Dermatol. Sci. 2010, 57, 114-122. [CrossRef] [PubMed]

13. Kong, R.; Cui, Y.; Fisher, G.J.; Wang, X.; Chen, Y.; Schneider, L.M.; Majmudar, G. A comparative study of the effects of retinol and retinoic acid on histological, molecular, and clinical properties of human skin. J. Cosmet. Dermatol. 2016, 15, 49-57. [CrossRef] [PubMed] 
14. Varani, J.; Warner, R.L.; Gharaee-Kermani, M.; Phan, S.H.; Kang, S.; Chung, J.H.; Wang, Z.Q.; Datta, S.C.; Fisher, G.J.; Voorhees, J.J. Vitamin A antagonizes decreased cell growth and elevated collagen-degrading matrix metalloproteinases and stimulates collagen accumulation in naturally aged human skin. J. Investig. Dermatol. 2000, 114, 480-486. [CrossRef] [PubMed]

15. Zhang, S.; Xuan, L. New phenolic constituents from the stems of Spatholobus suberectus. Helv. Chim. Acta 2006, 89, 1241-1245. [CrossRef]

16. Lee, M.H.; Lin, Y.P.; Hsu, F.L.; Zhan, G.R.; Yen, K.Y. Bioactive constituents of Spatholobus suberectus in regulating tyrosinase-related proteins and mRNA in HEMn cells. Phytochemistry 2006, 67, 1262-1270. [CrossRef]

17. Chen, S.R.; Wang, A.Q.; Lin, L.G.; Qiu, H.C.; Wang, Y.T.; Wang, Y. In vitro study on anti-hepatitis C virus activity of Spatholobus suberectus Dunn. Molecules 2016, 21, 1367. [CrossRef]

18. Lee, B.J.; Jo, I.Y.; Bu, Y.; Park, J.W.; Maeng, S.; Kang, H.; Jang, W.; Hwang, D.S.; Lee, W.; Min, K.; et al. Antiplatelet effects of Spatholobus suberectus via inhibition of the glycoprotein IIb/IIIa receptor. J. Ethnopharmacol. 2011, 134, 460-467. [CrossRef]

19. Peng, F.; Meng, C.W.; Zhou, Q.M.; Chen, J.P.; Xiong, L. Cytotoxic evaluation against breast cancer cells of isoliquiritigenin analogues from Spatholobus suberectus and their synthetic derivatives. J. Nat. Prod. 2016, 79, 248-251. [CrossRef]

20. Toyama, T.; Wada-Takahashi, S.; Takamichi, M.; Watanabe, K.; Yoshida, A.; Yoshino, F.; Miyamoto, C.; Maehata, Y.; Sugiyama, S.; Takahashi, S.S.; et al. Reactive oxygen species scavenging activity of Jixueteng evaluated by electron spin resonance (ESR) and photon emission. Nat. Prod. Commun. 2014, 9, 1755-1759. [CrossRef]

21. Im, N.K.; Lee, S.G.; Lee, D.S.; Park, P.H.; Lee, I.S.; Jeong, G.S. Spatholobus suberectus inhibits osteoclastogenesis and stimulates chondrogenesis. Am. J. Chin. Med. 2014, 42, 1123-1138. [CrossRef] [PubMed]

22. Pang, J.; Guo, J.P.; Jin, M.; Chen, Z.Q.; Wang, X.W.; Li, J.W. Antiviral effects of aqueous extract from Spatholobus suberectus Dunn. Against coxsackievirus B3 in mice. Chin. J. Integr. Med. 2011, 17, 764-769. [CrossRef]

23. Zhang, R.; Liu, C.; Liu, X.; Guo, Y. Protective effect of Spatholobus suberectus on brain tissues in cerebral ischemia. Am. J. Transl. Res. 2016, 8, 3963-3969.

24. Brito, S.M.; Coutinho, H.D.; Talvani, A.; Coronel, C.; Barbosa, A.G.; Vega, C.; Figueredo, F.G.; Tintino, S.R.; Lima, L.F.; Boligon, A.A.; et al. Analysis of bioactivities and chemical composition of Ziziphus joazeiro Mart. using HPLC-DAD. Food Chem. 2015, 186, 185-191. [CrossRef] [PubMed]

25. Kraunsoe, J.A.; Claridge, T.D.; Lowe, G. Inhibition of human leukocyte and porcine pancreatic elastase by homologues of bovine pancreatic trypsin inhibitor. Biochemistry 1996, 35, 9090-9096. [CrossRef] [PubMed]

26. Chou, T.C. Theoretical basis, experimental design, and computerized simulation of synergism and antagonism in drug combination studies. Pharmacol. Rev. 2006, 58, 621-681. [CrossRef] [PubMed]

27. Rigel, E.G.; Lebwohl, M.; Rigel, A.C.; Rigel, D.S. Daily UVB exposure levels in high-school students measured with digital dosimeters. J. Am. Acad. Dermatol. 2003, 49, 1112-1114. [CrossRef]

28. Zhao, P.; Alam, M.B.; Lee, S.H. Protection of UVB-induced photoaging by Fuzhuan-Brick tea aqueous extract via MAPKs/Nrf2-mediated down-regulation of MMP-1. Nutrients 2018, 11, 60. [CrossRef]

29. Bohm, M.; Schulte, U.; Kalden, H.; Luger, T.A. Alpha-melanocyte-stimulating hormone modulates activation of NF-kB and AP-1 and secretion of interleukin-8 in human dermal fibroblasts. Ann. NY. Acad. Sci. 1999, 885, 277-286. [CrossRef]

30. Son, Y.; Cheong, Y.-K.; Kim, N.-H.; Chung, H.-T.; Kang, D.G.; Pae, H.-O. Mitogen-activated protein kinases and reactive oxygen species: How can ROS activate MAPK pathways? J. Signal Transduct. 2011, 2011, 792639. [CrossRef]

31. Chouinard, N.; Valerie, K.; Rouabhia, M.; Huot, J. UVB-mediated activation of p38 mitogen-activated protein kinase enhances resistance of normal human keratinocytes to apoptosis by stabilizing cytoplasmic p53. Biochem. J. 2002, 365, 133-145. [CrossRef] [PubMed]

32. Rabe, J.H.; Mamelak, A.J.; McElgunn, P.J.; Morison, W.L.; Sauder, D.N. Photoaging: Mechanisms and repair. J. Am. Acad. Dermatol. 2006, 55, 1-19. [CrossRef] [PubMed]

33. Quan, T.; Qin, Z.; Xia, W.; Shao, Y.; Voorhees, J.J.; Fisher, G.J. Matrix-degrading metalloproteinases in photoaging. J. Investig. Dermatol. Symp. Proc. 2009, 14, 20-24. [CrossRef] [PubMed]

34. Niu, T.; Tian, Y.; Ren, Q.; Wei, L.; Li, X.; Cai, Q. Red light interferes in UVA-induced photoaging of human skin fibroblast cells. Photochem. Photobiol. 2014, 90, 1349-1358. [CrossRef] [PubMed] 
35. Fisher, G.J.; Kang, S.; Varani, J.; Bata-Csorgo, Z.; Wan, Y.; Datta, S.; Voorhees, J.J. Mechanisms of photoaging and chronological skin aging. Arch. Dermatol. 2002, 138, 1462-1470. [CrossRef] [PubMed]

36. Yang, D.J.; Moh, S.H.; Son, D.H.; You, S.; Kinyua, A.W.; Ko, C.M.; Song, M.; Yeo, J.; Choi, Y.H.; Kim, K.W. Gallic acid promotes wound healing in normal and hyperglucidic conditions. Molecules 2016, 21, 899. [CrossRef] [PubMed]

37. Maity, N.; Nema, N.K.; Abedy, M.K.; Sarkar, B.K.; Mukherjee, P.K. Exploring Tagetes erecta Linn flower for the elastase, hyaluronidase and MMP-1 inhibitory activity. J. Ethnopharmacol. 2011, 137, 1300-1305. [CrossRef]

38. Rojo de la Vega, M.; Krajisnik, A.; Zhang, D.D.; Wondrak, G.T. Targeting NRF2 for improved skin barrier function and photoprotection: Focus on the achiote-derived apocarotenoid bixin. Nutrients 2017, 9, 1371. [CrossRef]

39. Pittayapruek, P.; Meephansan, J.; Prapapan, O.; Komine, M.; Ohtsuki, M. Role of Matrix metalloproteinases in photoaging and photocarcinogenesis. Int. J. Mol. Sci. 2016, 17, 868. [CrossRef]

40. Sun, J. Matrix metalloproteinases and tissue inhibitor of metalloproteinases are essential for the inflammatory response in cancer cells. J. Signal Transduct. 2010, 2010, 985132. [CrossRef]

41. Ryu, J.; Park, S.J.; Kim, I.H.; Choi, Y.H.; Nam, T.J. Protective effect of porphyra-334 on UVA-induced photoaging in human skin fibroblasts. Int. J. Mol. Med. 2014, 34, 796-803. [CrossRef] [PubMed]

42. Wang, Y.; Lauer, M.E.; Anand, S.; Mack, J.A.; Maytin, E.V. Hyaluronan synthase 2 protects skin fibroblasts against apoptosis induced by environmental stress. J. Biol. Chem. 2014, 289, 32253-32265. [CrossRef] [PubMed]

43. Tanaka, K.; Asamitsu, K.; Uranishi, H.; Iddamalgoda, A.; Ito, K.; Kojima, H.; Okamoto, T. Protecting skin photoaging by NF-кB inhibitor. Curr. Drug Metab. 2010, 11, 431-435. [CrossRef] [PubMed]

44. Kwok, B.H.; Koh, B.; Ndubuisi, M.I.; Elofsson, M.; Crews, C.M. The anti-inflammatory natural product parthenolide from the medicinal herb Feverfew directly binds to and inhibits I-kB kinase. Chem. Biol. 2001, 8, 759-766. [CrossRef]

45. Huang, Y.-H.; Wu, P.-Y.; Wen, K.-C.; Lin, C.-Y.; Chiang, H.-M. Protective effects and mechanisms of Terminalia catappa L. methenolic extract on hydrogen-peroxide-induced oxidative stress in human skin fibroblasts. BMC Complement. Altern. Med. 2018, 18, 266. [CrossRef] [PubMed] 